\title{
Enhancing academic skills appointments through a new booking system
}

\section{Laurence Morris}

Leeds Beckett University

\section{Lindsey McDermott}

Leeds Beckett University

\section{Abstract}

This case study examines the introduction of a centrally managed booking system for academic skills appointments conducted by the Library Academic Support Team at Leeds Beckett University, showing how staff-student communication channels can scaffold effective student support. The new system was introduced in order to manage a large number of requests for skills appointments across all academic levels, to ensure an equitable experience for all learners, and to frame staff-student encounters more effectively at the formative stage. Further benefits included provision of more focused tuition, additional data on learner requirements, greater capacity to re-route appointment requests, and more efficient use of student and staff time, while retaining the option of human intervention in the system as required. This paper demonstrates a transferrable means of enhancing institutional processes whilst retaining the traditional strengths of oneto-one encounters in order to improve the overall student experience.

Keywords: academic support; appointments; booking system; communication; learning development; student experience. 


\section{Introduction}

Provision of effective academic skills tuition on an equitable basis across a university can be a significant operational challenge, with practical issues including managing demand and staff and student expectations, as well as understanding and responding to learner needs. This paper shows how the Library Academic Support Team (LAST) at Leeds Beckett University sought to address such challenges through the central management of their one-to-one skills appointments. A form-based booking system was introduced for the team's appointments, scaffolding learning encounters from the formative stage, easing student access to appropriate support, and providing fresh data on learner needs, while also retaining the capacity for human intervention in the system as required.

This case study examines the practical context of this activity, the underlying project aims, and the details of the intervention made. It also provides an initial interpretation of the new system's impact at Leeds Beckett, primarily relating to easier student access to a clear, consistent skills support offer across the institution, and increased capacity to identify and adapt to short-term changes in demand. In doing so, it demonstrates one means of achieving a more supportive institutional framework for learning development, while also highlighting generally transferrable principles and practicalities. It shows how to improve the student experience through agile provision of more effective support, while also harvesting data to provide greater awareness of learner needs in the longer term.

\section{Operational context and project aims}

Leeds Beckett University has approximately 25,000 students, taught across two campuses through full-time, part-time and distance learning courses. The LAST comprises approximately 20 full-time and part-time staff members, including Academic and Information Services Librarians, Academic Skills Tutors and other support staff. This team supports all levels from undergraduate to $\mathrm{PhD}$ across a range of areas, including referencing, academic writing, finding and using information, maths and IT. Support is provided on a tripartite basis: in-curriculum tuition; an open programme of workshops (comparable to that described in Blake et al., 2019); and bookable one-to-one appointments. The rationale for this structure is that it encourages independent learning, 
and that each stage offers supplementary support to the one which precedes it, if required. In practice, in a representative semester (Autumn 2019), some 325 one-to-one appointments were provided, supplementing approximately 500 in-curriculum and general tutorials and lectures delivered to group sizes ranging from 10 to $100+$.

In recent years, appointments have generally been booked directly with individual team members, resulting in inevitable local differences of practice, as well as the capacity for delay if a named contact was unavailable. Following a review of the LAST's activities, a small project group was instructed to develop 'a high quality, sustainable one-to-one support service for students to enhance their understanding and skills' (Howard, 2019). Specific sub-goals included provision of a simple booking system to allow students to access the appropriate support, a clear offer to staff and students, connectivity with other library services, a consistent, university-wide approach, the ability to share cover as required, capacity to manage enquiries and set expectations prior to appointments, and additional data on learner needs and their interaction with the service.

\section{Intervention}

The intervention implemented by the project group for academic year 2019-20 was a standardised booking form (see Appendix for form content) for one-to-one skills appointments with the LAST. Form submissions are managed from a central email inbox by team members, with either an appointment with a relevant team member or an alternative form of help - such as a direct answer to a simple question or redirection to online guidance - provided as appropriate. More specifically:

1. All appointment requests and comparable enquiries are channelled to the form, with direct bookings no longer accepted by staff.

2. The form is accessible via a button or link from the Library website and student support pages on the VLE and elsewhere. It is promoted to students by a range of library, course and support staff in person and across multiple platforms, often through simple provision of a direct link.

3. As shown in the Appendix, the form harvests the information required for an effective learning encounter at the point of booking, including student details, 
assignment topic, nature of help required, availability in the next fortnight, and any additional information required.

4. The form also highlights other potentially relevant support options and clearly states service standards such as appointment length, topics covered and the number of appointments requestable per student per semester (two, unless unusual circumstances apply and excluding in-curriculum and open workshop programme support).

5. After an appointment is conducted, a student's form data is retained to inform response to requests for further support and to aid wider service and curriculum planning. It is ultimately anonymised in accordance with organisational standards.

This system derives from the mandate to introduce a simple booking system for accessing the appropriate support in a consistent manner across the institution. Crucially, it addresses the operational issues arising from the historic practice of direct bookings, but without pre-empting any longer-term changes driven by evolving theory or further research, for example regarding appointment length and nature.

The intervention provides the following specific benefits:

- Framing student expectations of the learning encounter at a formative stage in the process.

- Enabling more effective tuition by harvesting the requisite information for adequate preparation at the point of booking.

- Enhancing the capacity to re-route appointment requests at times of high demand or limited staff availability.

- Using student and staff time more efficiently, by filtering out enquiries which can be resolved without an appointment.

- Ensuring more balanced provision of skills support across the university through the central management of learner requests.

- Collating fresh data on learner behaviour across the institution.

From an operational perspective, the intervention offers gains for minimal risk, with the only potentially adverse impact on learners being the gradual shift to a new, but nevertheless straightforward, means of requesting assistance. There were no fresh costs 
involved beyond the reallocation of staff time, with the IT systems used all straightforward tools already in use and supported in the university.

To minimise the extent of concurrent change, the administrative processes were an extension of those already used by the team, with a Springshare form used (later an MS form, due to wider organisational changes), a spreadsheet to manage form submissions, and then Outlook to conduct email correspondence, check staff availability and book appointments. There are a range of similar products available, and their suitability will vary with local needs, the salient point being that the intervention can be implemented with standard IT tools, with precise administrative processes adaptable to local practice.

\section{Implementation}

While the change was straightforward, it was made to a service delivered by 20 different people in different roles to approximately 25,000 students, all with their own expectations, work patterns and help-seeking behaviours (Alexitch, 2002). The form was therefore introduced at the start of a new academic year, when a moderate degree of change is expected, and when there are enhanced opportunities for communicating that change.

In practice, students adapted to the new booking system quickly, perhaps helped by its resemblance to other online processes. Staff engagement with the new approach took longer; the system was sometimes circumvented by effective existing relationships, or in response to a short-term student need. In such instances, in addition to stressing the longterm benefits of a standardised approach and the implications for equitable support if the new system was not consistently utilised, it was helpful to highlight the fact that form submissions were managed by LAST members and that human flexibility remained within the system. This was particularly important in view of the recommendation by O'Donnell et al. (2016) that diversity of student thought and action be accommodated by university staff, and the work of Jacklin and Le Riche (2009) and Roberts et al. (2018) on providing a supportive culture.

The operational impact of maintaining this flexibility - rather than adopting a fully automated system - should also be noted. The three LAST members who manage form 
submissions all have other roles, and all noted that the volume of work exceeded their expectations, with more submissions requiring some form of clarification than anticipated, for example regarding specific requirements or availability. However, the worth of such work was also noted, resolving potential issues in advance of an appointment and freeing up staff time elsewhere in the team.

\section{Impact, feedback and initial interpretation}

It is still relatively early in the operational life of the new system; in the longer term, more in-depth analysis of its impact and the data harvested on learner behaviour and needs across the institution will be conducted. However, even in the short-term, clear benefits were discernible.

The new system provided the anticipated benefits, with the number of appointments provided remaining consistent year-on-year, implying that any disruption caused during transition was minimal. Staff reported that through the human oversight of the booking process, they had been able to successfully address a significant number of enquiries not truly requiring an appointment by other means, such as providing an answer by email (particularly in the case of referencing) or by redirection to online guidance. As well as providing a faster response in those cases, with the overall number of appointments remaining the same, it can be inferred that the number of appropriate appointments rose.

Student feedback was positive, with the clear means of accessing a wide range of support and potentially swifter access to specialist advice (rather than having to potentially wait for a named individual) welcomed. Such individual feedback was also echoed by the Students' Union and course representatives at feedback forums on university-wide issues, reflecting the prominence of the changes to service. Interestingly, the increased prominence of service standards seems to have made appointments a more valuable commodity to students. Previously, some students had regarded the available support as more of a personal tutoring service, booking multiple appointments with multiple staff members, or in a broad range of subjects, whereas the new system scaffolds a more strategic approach. It encourages individuals to reflect in order to focus an appointment on 
a specific learning challenge, such as using feedback to improve writing skills, thereby supporting the evolution of a student-centred learning environment (Hoidn, 2017). Academic staff welcomed this, as well as the central means of access to a range of support and the greater capacity for service-wide flexibility when required. Equally, colleagues in other university services, such as the Student Hub, requested briefings in how best to engage individuals with the new system where required, improving the interconnectivity of university-wide student support.

Colleagues within the LAST have praised the effective management of appointment bookings and the provision of information upon which to base focused appointments. While some colleagues have rightly noted the shift from relative local autonomy, they have also noted the student-facing and university-wide benefits of the standardised approach. Although online forms are not an ideal means of requesting assistance for all students, it is accepted that such mechanisms are a standard means of obtaining detailed information, and the use of team members to manage bookings ensures that alternative communication channels remain in place where required. The form already followed standard principles of usability (Krug, 2014), but it was further streamlined for a simpler user experience on the basis of colleague feedback, with the realisation that it was preferable to request additional details as required rather than to force all learners to submit extensive information, and that the individual management of form submissions enabled such flexibility.

General service delivery has also been helped by the assembly of a more comprehensive bank of information about the LAST's activities as they are conducted, rather than retrospectively, as was previously the case. This information has enabled more effective planning and targeting of services, helping to ensure more balanced support is provided overall. In the short term, it is more straightforward to see where local and university-wide peaks and troughs of demand are, and to respond accordingly, reallocating staff time as required. However, in doing so, it is also easier to ensure that one particular cohort does not receive a disproportionate level of support. The tracking of demand makes it easier to identify anomalies and, if necessary, provides the evidence to suggest to a course or module leader that there is a need for further in-curriculum skills tuition. Additionally, even where such issues are not a factor, the system still underpins more balanced support for 
all learners through the standardisation of booking and service standards, reducing the capacity for unintentional local discrepancies of practice.

\section{Covid-19}

The agility and robustness of the new system were unexpectedly demonstrated by the operational changes required by the coronavirus outbreak. When Leeds Beckett's physical library and teaching spaces were closed, the LAST provided skills support online and by telephone. The appointment management system meant that it was straightforward to implement and publicise changes, to provide a consistent response to learners across the institution, and to adjust support as required.

Capacity for such action had not been a specific factor in planning, but it proved useful in adapting to an unanticipated challenge. In particular, the deliberate retention of human judgement within the management process ensured flexibility where required, from providing additional appointments to delivering them through unusual platforms such as Instagram. In practice, after an initial fall, demand soon increased as students adapted to working from home, and even where one-to-one assistance was not required, academic staff and students commented that its continued availability - alongside other library services - provided reassurance at a challenging time.

\section{Further interpretation and action}

While the intervention fulfilled its initial goals, it would be worth reviewing the broader effectiveness of fine-tuning the delivery of a popular but ultimately time-expensive service (Turner, 2010). Future evaluative work will therefore use more comprehensive student feedback, more in-depth analysis of the harvested data and quantitative impact analysis to explore why this form of support is so popular and whether the same ends could be achieved by alternative means. Some form of Socratic or didactic encounter might well remain a key component of learning, but it could be that the end result valued by students could also be supported by other means, such as the further development of a culture of independent learning. Equally, it may be worthwhile considering the implications for practice of rendering traditional roles more interchangeable, from an operational 
perspective, but also in relation to the work of Lea and Street (2006), Wingate (2006) and others, on the ultimate limitations of more generic forms of instruction.

In positing such dilemmas, it is emphasised that the system adopted by Leeds Beckett's LAST is only one approach, for a specific set of local circumstances. However, the future resolution of such questions at Leeds Beckett will now be informed by additional data on learner behaviour and needs, about how, when and why students learn, and about the impact of local and disciplinary differences of practice. Once a full year of data is available, we look forward to analysing it in more detail.

\section{Conclusion}

This case study has outlined how the LAST at Leeds Beckett University introduced a formbased booking system for one-to-one appointments in academic skills, while retaining capacity for human intervention in the system. This intervention was made in order to scaffold the provision of more effective appointments, frame staff-student encounters at a formative stage, enhance service agility and provide a more equitable service. In addition to the particular intervention detailed, the transferrable principles and operational factors elucidated may be of interest to other services considering similar changes.

Ultimately, the impact of the new Leeds Beckett LAST system was underpinned by various factors, but particularly the provision to the project group of both a clear goal and significant practical flexibility in achieving it. This directly contributed to the distinctive elements of the system adopted, such as the retention of human judgement within a more process-driven framework, and the consequent impact on both system agility and staff and student engagement. Harnessing existing knowledge in this way was the harbinger of what will follow, as the focus now shifts from short-term impact to using the resultant data on student needs and behaviour to inform future learning development activity at Leeds Beckett University. 


\section{References}

Alexitch, L. R. (2002) 'The role of help-seeking attitudes and tendencies in students' preferences for academic advising', Journal of College Student Development, 43(1), pp.5-19.

Blake, J. R. S., Grayson, N. and Karamalla-Gaiballa, S. (2019) 'Investigating impact: exploring the effect of 'open' support on student success', Journal of Learning Development in Higher Education, 0(16).

Hoidn, S. (2017) Student-centered learning environments in higher education classrooms. New York: Palgrave Macmillan.

Howard, H. (2019) Library Academic Support: 2017-2021 Plan. Leeds: Leeds Beckett University.

Jacklin, A. and Le Riche, P. (2009) 'Reconceptualising student support: from 'support' to 'supportive”, Studies in Higher Education, 34(7), pp.735-749.

Krug, S. (2014). Don't Make Me Think, Revisited: A Common Sense Approach to Web Usability. $3^{\text {rd }}$ ed. San Francisco: New Riders.

Lea, M.R. and Street, B.V. (2006) 'The "academic literacies" model: theory and applications'. Theory Into Practice, 45(4), pp.368-377.

O’Donnell, V., Kean, M. and Stevens, G. (2016) Student transition in Higher Education: concepts, theories and practices. York: HE Academy. Available at: https://www.heacademy.ac.uk/system/files/resources/student transition in higher education.pdf (Accessed: 9 May 2020).

Roberts, P. A., Dunworth, K. and Boldy, D. (2018) 'Towards a reframing of student support: a case study approach', Higher Education, 75(1), pp.19-33. 
Turner, J. (2010) 'The case for one-to-one academic advice for students', in Hartley, P., Hilsdon, J., Sinfield, S., Keenan, C. and Verity, M. (eds.) Learning development in higher education. London: Palgrave Macmillan, pp. 91-101.

Wingate, U. (2006) 'Doing away with 'study skills'. Teaching in Higher Education, 11(4), pp.457-469.

\section{Author details}

Laurence Morris is an Academic Librarian at Leeds Beckett University, a Senior Fellow of Advance HE and a Fellow of the Royal Geographical Society. His present role primarily involves supporting students, staff and researchers in accessing and applying relevant information effectively. He has previously worked with online reading systems and in information provision for the Ministry of Defence.

Lindsey Mcdermott is an Administrator in the Library Academic Support Team at Leeds Beckett University, where she has worked for the past 6 years. She is responsible for organising a programme of academic skills workshops, manages student appointment requests and is a member of the working group which recently redesigned the Library Academic Support Team's staff-student appointment system.

\section{Appendix: The form}

The questions and text used in the form are given below. Leeds Beckett's LAST uses MS Forms for the form at present, but other tools such as Google Forms and Springshare's LibWizard would have a comparable effect. The first two questions were preferred to autopopulation by single sign-on systems for ease of use when university staff are referring students to the service.

\section{Preamble}

Are you aware of the different kinds of help available from the Library?

- $\quad$ Link to $24 / 7$ enquiry service. 
- Link to referencing guidance.

- Link to subject-specific guidance.

- Link to academic skills guidance.

If these options don't cover your question, you can request an appointment. We have a limited number available, so please try to request any help well in advance.

\section{Questions}

1. What is your name? [Text answer]

2. What is your university email address? [Text answer]

3. What is your course or subject area? [Text answer]

4. Which year are you in? [Choice from a menu: level $4 /$ first year undergraduate to $\mathrm{PhD} / \mathrm{staff]}$

5. What do you need help with? [Choice from a menu: finding and using information, referencing, academic writing or presentations, maths or statistics, other]

6. Please describe what help you require, or anything else we need to know (for example, what your assignment topic is, or any specific learning needs). [Text answer]

7. When are you available in the next two working weeks? Please give specific dates and times. [Text answer]

Note: A question on whether a face-to-face or online/telephone appointment is preferred is not currently in use due to the Covid-19 pandemic resulting in the temporary closure of university buildings.

\section{Pre-submission text}

We will arrange an appointment for you if we are unable to assist you by email. Students can generally book a maximum of 2 appointments with us per semester. They are 30 minutes long and available Mon-Fri in office hours, subject to staff availability. We can give you pointers on how to improve your academic skills and can help you improve upon your previous work. We are unable to check drafts or proofread work, but we can help you work more effectively as an independent learner.

\section{Post-submission text}

Thank you for contacting us. We will get back to you within 3 working days. 